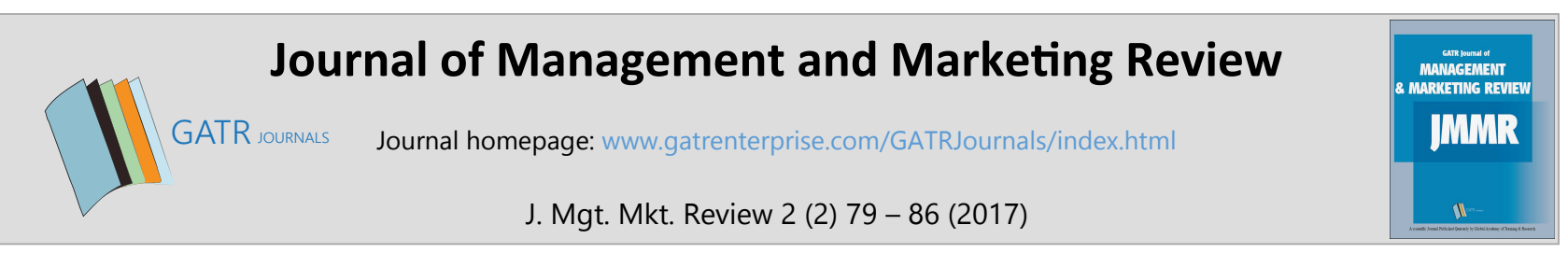

\title{
Do Web Atmospherics Affect Purchase Intention? The Role of Color and Product Display
}

\author{
Kharina Dwinanda Putri ${ }^{1 *}$ and Tengku Ezni Balqiah ${ }^{2}$ \\ ${ }^{1}$ Magister Management-Universitas Indonesia, Salemba, Indonesia \\ ${ }^{2}$ Faculty of Economics and Business, Universitas Indonesia, Depok, Indonesia
}

\begin{abstract}
Objective - The growth of online retailers has increased competition in online business. This situation has forced online retailers to design web atmospherics more attractively. This empirical study examines how web atmospherics, namely, web color and product display, will influence visitor responses.

Methodology/Technique - The method was experimental design. Using factorial design and ANOVA, this paper investigates whether cool colors (versus warm) and models (versus without a model) generate more positive emotional arousal, attitude, and purchase intention. Four artificial websites, based on a combination of web color and product display (with versus without model), were developed; 120 participants evaluated each website between subjects.

Findings - The result show that a cool color, with a model on the product display, can stimulate emotions and more positive attitude toward a website than any other combination. Furthermore, it will encourage purchase intention.

Novelty - This research combines color and human models to offer apparel products on an artificial website. The combination can be implemented in a real apparel website to optimize an online business.
\end{abstract}

Type of Paper: Empirical

Keywords: Website Color; Product Display; Customer Response, ANOVA.

JEL Classification: M31, M37.

\section{Introduction}

Although the number of Internet users has increased in last five years, this condition does not guarantee online sales, especially in ASEAN countries. In Southeast Asia, there are more than 250 million smartphone users, but only one in four consumers over the age 16 has made an online purchase (Hoppe, Lamy, \& Cannarsi, 2016). Online sales are still low in ASEAN countries; only $1 \%$ of total retail sales are in Indonesia, Malaysia, Philippines, Singapore, Thailand, and Vietnam (DBS Asian Insight, 2015). In Indonesia, online sales in 2014 were only $0.7 \%$ of total sales, such as through entertainment media, electronics, fashion, and tourism.

In 2016, Internet penetration in Indonesia reached 40 percent of the population, or 100 million Internet users (The Association of Internet Service Providers in Indonesia [APJII], 2016). One-third of the Indonesian

\footnotetext{
* Paper Info: Received: November 11, 2016

Accepted: May 6, 2017

* Corresponding author:

E-mail: kharina.dwinanda@gmail.com

Affiliation: Magister Management-Universitas Indonesia, Indonesia
} 
population are active social media users, not only for communication but also to use e-commerce platforms for small and midsized enterprises (Indonesia-Investment, 2016). Thus, the potential market is high.

This high potential market will attract more online retailers, both in mixed-channel and pure online retailers. Online retailers are the terms in which the retailer operates only through the website (Keller, 2013). There are potential aspects and implications of online retailing for buyers and sellers that could promote a business. This is the reason why more retailers are considering online trading in doing business (Eroglu et al., 2001): the operating cost is lower than in the retail-based store (Euromonitor, 2015).

Meanwhile, from the consumers' perspectives, online shopping offers the convenience of being both temporal and spatial, thus offering value through the opportunity to compare prices, which increases the likelihood of hedonic consumption (Eroglu et al., 2001). There are access, search, evaluation, transaction, possession, and post-purchase convenience dimensions in online shopping (Jiang, Yang, \& Jun, 2013). Sustaining a high level of online shopping convenience and offering competitive prices has become a key driving force for online retailers, with the aim of enhancing customer loyalty. The success of online retailers depends on their ability to ensure that consumers do not just visit a website but also spend sufficient time to explore the site. To achieve this goal, the web designer and manager must understand how consumers choose a certain website among a wide selection of sites, how consumers interact with the web and evaluate the web design interface, and how consumers make purchases through a website (Eroglu et al., 2001).

Based on the above explanation, the problem in this research is whether there are differences in responses in terms of positive emotion, attitudes, and purchase intention arising from different apparel product displays and web colors. Further, we also need to examine whether emotion could influence attitude and purchase intention.

\subsection{Stimulus-Organism-Response}

A stimulus-organism-response (S-O-R) account of how the physical environment affects the internal state and behavior of people (Faryabi et al., 2015). Wu et al. (2014) suggested that this framework provides a structure in which to identify the relationship between stimuli from the environment (stimulus), the organism, and its response. The framework of S-O-R is conceptualized as a stimulus effect that evokes the emotions of an individual (Eroglu et al., 2001). Stimulation from the environment or stimulus (S) will affect a person's internal state $(\mathrm{O})$ and responses from audiences $(\mathrm{R})$. In the context of online retailing, the stimulus can be defined as the sum total of all visible and audible cues for online shoppers.

Consumer attitudes to the website also will be assessed at the organism stage ( $\mathrm{Wu}$ et al., 2014). The organism is described by the state as affective and cognitive processes that intervene in the relationship between stimulus and response of an individual, such as fun (pleasure), excitement (arousal), and domination (Eroglu et al. 2001). In the last phase, the response of consumers is related to consumer purchase intentions after visiting a website (Wu et al., 2014). According to the framework of S-O-R, this is the response of consumers referring to the behavioral approach or avoidance behavior, which is a consequence of a person's affective and cognitive state (Eroglu et al., 2001).

\subsection{Website Atmospheric}

Dailey (2004) defined website atmospheric as the creation of a website to create a positive effect on the user, for example, positive cognition and affection. The web atmosphere, which is defined as being a set of atmospheric cues, includes a wide range of colors, sounds, layouts, speeds, navigation instructions, and so forth (Dailey, 2004). Conventionally, this is the term used to describe space atmospherics and to design a store. Currently, the term is also used in the atmospheric environment of e-commerce to describe the layout and design of a store's website (Abbott et al., 2000).

Eroglu et al. (2001) also explained that the atmosphere of an online store can be divided into information classified as high task and low task. High task cues include all descriptions on the website, either in writing or 
as images, which appear on the screen, as well as facilitating and enabling achievement of the consumers' goals. High task cues include all descriptions about the product, price, terms of sale, delivery and return policies, product images, and navigation systems that facilitate consumer usage on the website. The purpose of the high task is to guide shoppers into achieving their goals. On the other hand, low task cues refer to all information not associated with consumer spending activity. Low task cues include colors, borders, patterns on the background, fonts, animations, music and sounds, entertainment in the form of a games or contests, other than product images, web counters, and awards as well as the affiliate website. In this study, the authors use color and product image as stimuli.

\subsection{Conceptual Framework}

In the context of online shopping, web atmospherics act as stimuli that trigger certain emotional states of a shopper, leading either to positive or negative experiences (Kawaf \& Tagg, 2017). Eroglu et al. (2001) explained how the online shopping environment influence experience, namely, web atmospherics, SOR adaptation, web design, and web quality. Eroglu et al. (2001) argued that web design must be considered because it plays an important role in influencing consumer purchase intentions. Display or product images and web color were explained by Wu et al. (2014), who adopted a framework stimulus-organism-response (S-O$\mathrm{R}$ ) as an effort to develop a conceptual model of an online retail store. The stimulus-organism-response (S-OR) framework was initiated by Mehrabian and Russell (1974; in Wu et al., 2014) to provide a framework in which to identify the relationship among stimuli from the environment, organisms, and response. Thus, the S$\mathrm{O}-\mathrm{R}$ framework provides a structure in which to identify the relationships among the stimuli $(\mathrm{S})$ of the environment, organism $(\mathrm{O})$, and response $(\mathrm{R})$.

Product display and web color are the stimuli (S) that can be classified as an aspect of atmospherics. The atmosphere concern about the design and various other aspects to influence the buyers (Kotler, 1973; in Solomon, 2013). These stimuli cause different reactions from visitors. This reaction can be seen as emotions, attitude during or after exploring the website, as well as purchase intentions through the website. Emotions and attitudes belong to the stage of the organism (O) in the framework of S-O-R. Further, the final response of consumers $(\mathrm{R})$ is related to consumer purchase intentions. Purchase intention refers to the probability and the willingness of people to buy through the website and is an appropriate indicator to measure consumer response after visiting a website (Wu et al., 2014).

Based on the S-O-R model, the online environmental cues or stimuli (i.e., web color and product display by model or without model) would influence the affective and cognitive reactions (i.e., the internal states of the organism), finally approach/avoidance behaviors (i.e., the response).

\subsection{Research Objective and Hypotheses}

In Indonesia, there is still limited study that focuses on the effectiveness of web atmospherics, especially on product display and web color, and how web atmospherics can influence visitors. This study was conducted to determine the effect of the web atmospherics on emotion and visitor behavior. First, whether the product's display (with and without model) and web color (cool and warm) could create positive emotion, attitudes, and purchase intention. Second, whether emotions could influence attitude and further purchase intention. 


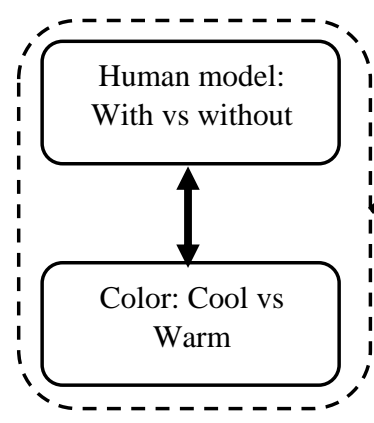

Stimulus

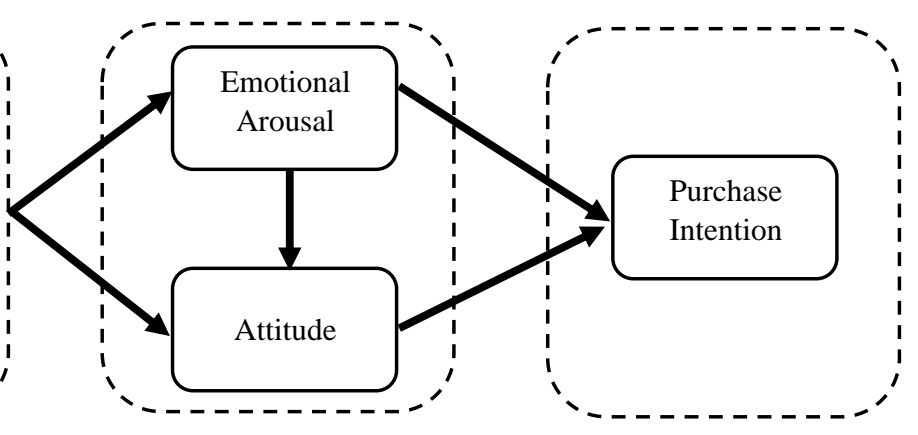

Organism

Response

Figure 1. Research Model

Regarding the S-O-R framework, this study investigated the effectiveness of web atmospherics in enhancing emotion and behavior. Then and DeLong (1999) emphasized the importance of using human models in the product display to show how clothing looks when it is worn. Hong (2001) stated that web design plays an important role in influencing consumer attitudes to the web. Favorable web designs are conducive to generate more positive attitudes. Faryabi et al. (2015) suggested the combination of colors on the web can influence customers' perception of the store as well as encourage them to visit and purchase through the web. Pleasure and arousal are also affected by color. Color can contribute not only to differentiate the product from that of the competitors but also can affect mood and feelings (Singh, 2006). Valdez and Mehrabian (1994) stated that color with shorter wavelengths is able to induce pleasure. Cool colors such as blue-green and green also evoke emotion or passion. Hence, this study offers the following hypothesis:

H1: Emotional arousal will be higher when it uses a human model and cool color

$\mathrm{H} 2$ : Attitude will be higher when it uses a human model and cool color

Lee et al. (2003) found that emotion, including arousal, will significantly affect positive consumer attitudes. Therefore, this study offers the following hypothesis:

H3: Emotional arousal positively influences attitude toward a website.

Baker et al. (2002) also stated that the emotional state of consumers is positively related to consumers' willingness to make a purchase. Referring to the S-O-R framework, a response can be seen as the result of an approach or avoidance behavior. Therefore, this study offers the following hypotheses:

H4: Emotional arousal positively influences purchase intention.

H5: Attitude positively influences purchase intention.

\section{Method}

\subsection{Research Design}

This study uses factorial design (2x2). The factors are product image represented by a human model (with versus without model) and web color (warm versus cool). The dependent variables are the consumer response after visiting an artificial website: emotions, attitudes, and purchase intentions. There are some extraneous variables: website content, selection of products available on the web, information about the product (brand, price, product description, care instructions). The authors controlled all these variables by developing four artificial websites. 


\subsection{Development of Stimuli and Manipulation Check}

The classification into warm and cool colors is based on a study by Valdez and Mehrabian (1994). In a pretest, 30 participants were asked to choose one color as a dominant color for the web, for each category, without knowing if the category was warm or cool. Ten colors in the Munsell color system were used (Figure 2). The left side is a warm color, and the right side is cool. The result demonstrates that last color on the left side was chosen as the warm color and the second color on the right side as the cool color. Combining these two colors and the human model, there are four stimuli that refer to four artificial websites (see appendix).

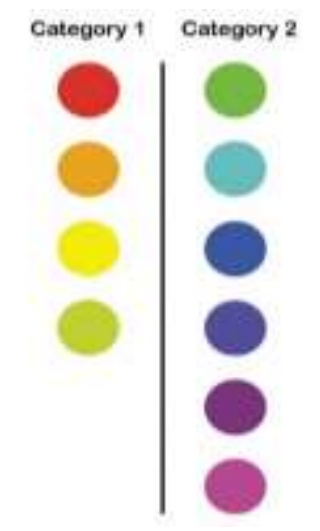

Figure 2. Categorized Colors

\subsection{Samples}

A total of 120 participants completed the experiments. For this purpose, a purposive sampling technique was used to obtain the participants. The participants are between the ages of $31-40$ years old; $82 \%$ are married; $47.6 \%$ are married; $56.7 \%$ have a bachelor degree; and $81.7 \%$ have experience in online shopping.

\subsection{Measurement and Data Analysis}

Using a 7-point Likert scale, there are seven items to manipulation check of color adapted from Bellizzi dan Hite (1992). Emotional arousal was measured using 16 items (Mummalaneni, 2005). The attitude was measured using eight items, and purchase intention was measured using four items adapted from Kraft et al. (2005). ANOVA and multiple regression were conducted to test the hypotheses.

\section{Result and Discussion}

\subsection{Hypothesis Testing}

The highest mean score of emotional arousal toward a website is when the site used models and cool colors (mean=5.63) (Figure 3). In this study, green-blue represents cool. The test results are consistent with those of Valdez and Mehrabian (1994), which described that the green-blue color was classified as creating the most feelings of pleasure. This condition was related to the level of pleasure. Valdez and Mehrabian (1994) also said that the blue-green color is in the second order of the most colors that can evoke emotions or passion of a person, where the first is a yellow-green color as one of the relatively warm colors, which is associated with a person's level of arousal. Emotion also is related to the use of human models. When products are displayed by using the model, consumers will feel more comfortable to shop (Shih, 1998). This result supports H1. 


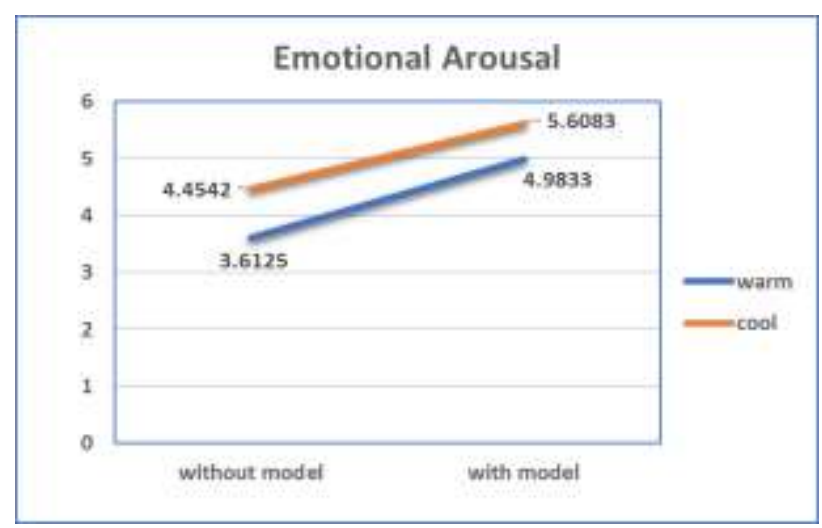

Figure 3. Emotional Arousal

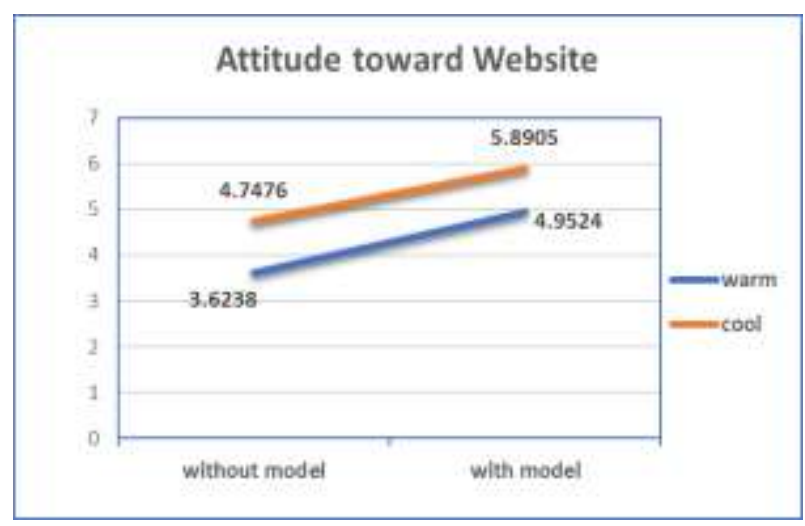

Figure 4. Attitude Toward a Website

Attitudes toward a website that uses models and cool colors have the highest mean score (5.8905) (Figure 4). In the context of online shopping for specialty apparel, risk is decreased, which is related to increasing product information because product display is a method to provide information (Kim et al., 2009). According to Spies et al. (1997), a person is more likely to make a purchase and spend more money when there is a positive mood than someone with a negative mood. Hence, there is a possibility in the importance of interactions between the mood of the customers and their buying behavior. Bellizzi and Hite (1992) states that an environment with cool colors is able to encourage consumers to explore and shop the web and reduce the delay purchase of a product. This result supports $\mathrm{H} 2$.

There is positive influence of emotional arousal toward attitude $(B=0,634: p=0.000)$. These results indicate that the higher the level of emotions arouse after accessing a website, the more positive attitude toward the web. The level of emotion encompasses feeling happy, cheerful, happy, satisfied, excited, enthusiastic, realized, and passionate (Mehrabian \& Russell, 1974; Mummalaneni, 2005). These emotions lead to positive attitude toward a website such as comfort and increased attractiveness. Consumers are happy to spend time while exploring a website, as well as purchasing through the web; it is good and pleasant when they decide to make a purchase through the web (Kraft et al., 2005). This result supports H3.

Further, there is the positive influence of emotional arousal toward purchase intention $(B=0,336: p=0.000)$ and attitude toward purchase intention $(B=0,491: \mathrm{p}=0.000)$. In line with these results, Menon and Kahn (2002) revealed that pleasure encourages the approach behavior. Pleasure also encourages the desire to seek stimulation in the next event. Purchase intention is an approach behavior that is often used in the context of online shopping (Eroglu et al., 2003), as demonstrated by consumers who increasingly intend to buy, most likely to purchase, consider buying, or are planning to make a purchase through the web in the future (Kraft et al., 2005). This result supports $\mathrm{H} 4$.

Eroglu et al. (2001) states that the consumer response refers to the approach or avoidance behavioral. Approach or avoidance behavioral is a consequence of affective state and a person's cognitive. Approach behavior includes responses that are positive, such as consumer purchase intentions. Previous studies revealed that the attitude toward a favorite clothes' website will affect intention-not just to find information on the web but also to buy clothes from the web (Seock \& Norton, 2007). This result supports H5. Based on these results, the research model following the S-O-R model was confirmed.

\section{Conclusion}

This study confirms the S-O-R framework in an artificial fashion website. The result shows that web design that uses a dominant cool color as well as a human model can evoke emotions, thus creating a more positive attitude toward the website than other combinations. Furthermore, it will encourage the purchase intention of clothing products being offered. Online retailers can use a human model with a product display to reduce the consumer risk perception because online purchases are considered a higher risk than purchases in stores, 
especially in the context of buying clothes. Through using the human model, online retailers can provide additional information about the product, which will help to intensify a consumer's positive belief in the product. Use of a human model helps to enhance positive emotion and consumer attitudes and increase intention to purchase through the web.

This study suggests that the use of cool colors is able to cause more positive emotions and attitudes. The use of cool colors inspires consumers to feel happy, cheerful, and satisfied. The use of cool colors also leads to consumers being happy to spend more time to explore a website and finally willing to make a purchase through the web. Hence, online retailers need to pay attention to the importance of web visual design. This will help generate a positive response and attract consumer attention. But one should be careful in applying the results because these results from an experimental design have low external validity. Thus, the author recommends future research using an actual website through surveys as well as the use of other colors and different products.

\section{References}

Abbott, M., Chiang, K. P., Hwang, Y. S., Paquin, J., \& Zwick, D. (2000). The process of on-line store loyalty formation. Advance in Consumer Research, 27, 145-150.

Baker, J., Parasuraman, A., Grewal, D., \& Voss, G. B. (2002). The influence of Multiple Store Environment Cues on Perceived Merchandise Value and Patronage Intentions. Journal of Marketing, 66(2), 120-141.

Bellizzi, J. A., and Hite, R. E. (1992). Environmental color, consumer feelings, and purchase likelihood. Psychology \& Marketing, 9(5), 347-363.

Dailey, L. (2004). Navigational web atmospherics: explaining the influence of restrictive navigation cues. Journal of Business Research, 57(7), 795-803.

Eroglu, S. A., Michelet, K. A., \& Davis, L. M. (2001). Atmospheric qualities of online retailing: a conceptual model and implications. Journal of Business Research, 54(2), 177-184.

Faryabi, M., Fesaghandis, K. S., \& Saed M. (2015). Brand name, sales promotion and consumers' online purchase intention for cell-phone brands. International Journal of Marketing Studies, 7(1), 167-179.

Hong, W. (2002). The Impact of Web Interface Characteristics on Consumer Online Shopping Behavior (Dissertation, The Hong Kong University of Science and Technology, Hong Kong). Retrieved from www.proquest.com.

Jiang, L. (Alice), Yang, Z., \& Jun, M. (2013). Measuring consumer perceptions of online shopping convenience. Journal of Service Management, 24(2), 191-214.

Keller, K. L. (2013). Strategic brand management: building, measuring, and managing brand equity ( $4^{\text {th }}$ ed), England: Pearson Education Limited.

Kim, J., Kim, M., \& Lennon, S. J. (2009). Effects of web site atmospherics on consumer responses: music and product presentation. Direct Marketing: An International Journal, 3(1), 4-19.

Kraft, P., Rise, J., Sutton, S., \& Roysamb, E. (2005). Perceived difficulty in the theory of planned behaviour: perceived behavioural control or affective attitude? British Journal of Social Psychology, 44(3), 479-496.

Lee, M. B., Suh, K. S., \& Whang, J. (2003). The impact of situation awareness information on consumer attitudes in the Internet shopping mall. Electronic Commerce Research and Applications, 2(3), 254-265.

Lee, S. \& Rao, V. S. (2010). Color and store choice in electronic commerce: The explanatory role of trust. Journal of Electronic Commerce Research, 11(2), 110-126.

Menon, S., \& Kahn, B. (2002). Cross-category effects of induced arousal and pleasure on the Internet shopping experience. Journal of retailing, 78(1), 31-40.

Mummalaneni, V. (2005). An empirical investigation of web site characteristics, consumer emotional states and online shopping behaviours. Journal of Business Research, 58(4), 526-532.

Seock, Y. K. \& Norton, M. (2007). Attitude toward Internet websites, online information search, and channel choices for purchasing. Journal of Fashion Marketing and Management, 11(4), 571-586.

Shih, C. F. (1998). Conceptualizing consumer experiences in cyberspace. European Journal of Marketing, 32(7/8), 655663.

Singh, S. (2006). Impact of color on marketing. Management Decision, 44(6), 783-789.

Solomon, M. R. (2013). Consumer behavior (10 ${ }^{\text {th }}$ ed), England: Pearson Education Limited. 
Spies, K., Hesse, F., \& Loesch, K. (1997). Store atmosphere, mood and purchasing behavior. International Journal of Research in Marketing, 14(1), 1-17.

Then, N. K., \& Delong, M. R. (1999). Apparel shopping on the Web. Journal of Family and Consumer Sciences, 91(3), 65.

Valdez, P., \& Mehrabian, A. (1994). Effects of color on emotions. Journal of experimental psychology: General, 123(4), 394.

Wu, W. Y., Lee, C. L., Fu, C. S., \& Wang, H. C. (2013). How can online store layout design and atmosphere influence consumer shopping intention on a website?. International Journal of Retail \& Distribution Management, 42(1), 4-24.

\section{Appendix}

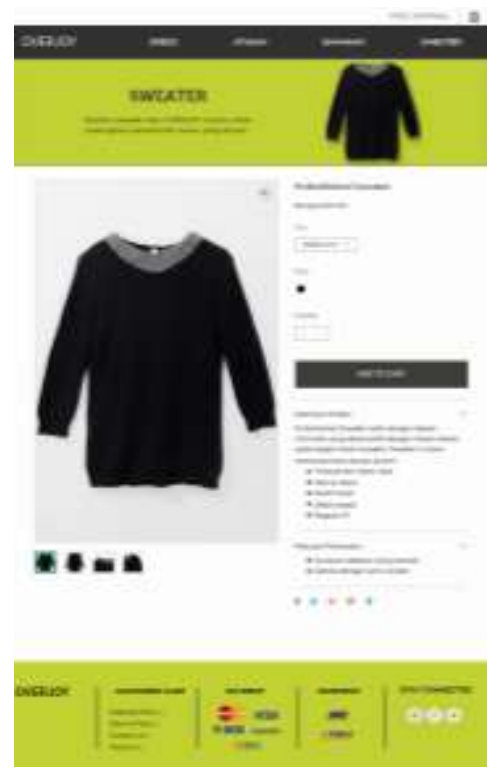

Warm: without Model

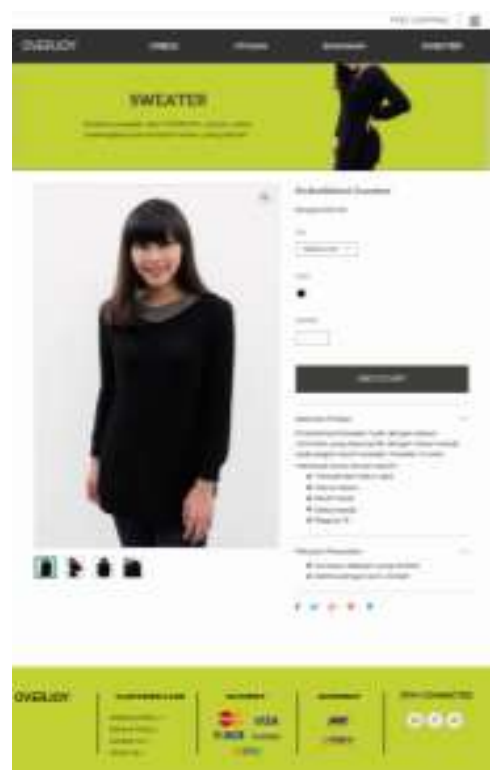

Warm: with Model

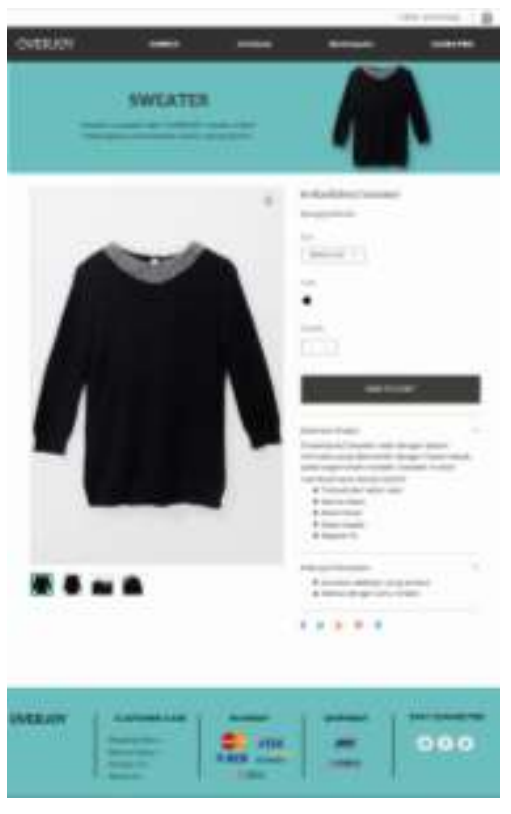

Cool: without Model

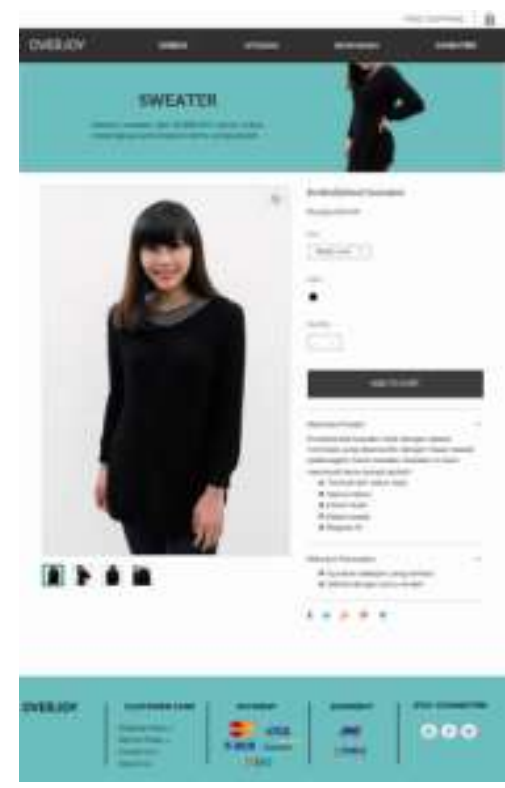

Cool: with Model 